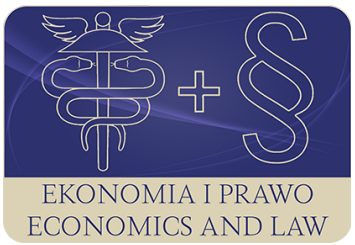

EKONOMIA I PRAWO. ECONOMICS AND LAW

Volume 17, Issue 3, September 2018

p-ISSN 1898-2255, e-ISSN 2392-1625

www.economicsandlaw.pl

ORIGINAL ARTICLE

received 02.01.2018; revised 25.03.2018; accepted 30.09.2018

Citation: Piosik, M. (2018). Mainstreams of research on institutional change in the multidimensional viewpoint. Ekonomia i Prawo. Ecomomics and Law, 17(3): 279-287. doi:10.12775/EiP.2018.020.

\title{
Mainstreams of research on institutional change in the multidimensional viewpoint
}

\section{MAREK PIOSIK}

Poznań University of Economics and Business, Faculty of International Business and Economics, Department of International Competitiveness, al. Niepodległości 10, 61-875 Poznań, Poland

๑ piosik.m@gmail.com

\begin{abstract}
Motivation: The role of institutions in the social and economic development is widely recognized in recent literature on economics of institutions. Economic history provides many examples of bad and good institutional structures, environments, and ways of organizing the social life and relationships between individuals, which is the main reason for institutions to arise. Simultaneously diversity of institutional solutions can be perceived as cultural wealth from which societies can choose in order to find proper instruments to solve various problems in different situations.

Aim: The present paper is an attempt to review main areas of research into institutional changes and synthesize them into mainstreams, which are also described in the multi-faceted viewpoint to prove the complexity and broad scope that need to be tackled by institutional economists to investigate institutional changes.

Results: The article analyses literature on institutional change and several dozen dimensions of the research areas that have a significant impact on the discussion on the mechanisms and environments of evolution of institutions. The review of the mainstreams is divided into five identified basic groups. In the result's section the multidimensional perspective of the research area of institutional changes is proposed as it helps to grasp many aspects that play the fundamental role in understanding the process of institutional change, which is an indispensable step towards a development of the general theory

of institutional change.
\end{abstract}


Keywords: institutions; institutional change; theory of institutional change; evolution of the institution

JEL: B52; D02; O17; O43

\section{Introduction}

The analysis of institutional change requires deep knowledge of numerous theories, aspects and dimensions of studies regarding institutions deriving from diverse disciplines of economics. Since there are few papers dealing with a general overview of such a wide scope of this research area, it is hard to grasp the complexity that needs to be tackled by institutional economists to investigate institutional changes.

Hence, the main purpose of this paper is to synthesize the current main streams of institutional change research through comprehensive literature analysis and review of identified essential dimensions of institutional change. The second objective is to propose a multi-faceted perspective of the institutional changes research that will help to understand the variety of components that play vital role in understanding the process of institutional change

\section{Literature review}

The first group of studies that have an impact on institutional changes is the elementary institutional field, which focuses on investigating the very basic definition of institutions and its borders, its typology and, first and foremost, the elements of the grammar of the institutions. D. North (1990, pp. 3-5) defines institution as 'a rule of the game' and S.E.S. Crawford and E. Ostrom (1995, pp. 582-583) distinguish three meanings: equilibrium, norms, and rules. The widely accepted typology of institutions in terms of investigating the institutional change is based on criteria of arrangement and environment (Davis \& North, 1970, p. 133) and slow-moving vs. fast-moving institutions (Roland, 2004, pp. 109-131). Little agreement exists as to how to undertake a cumulative study of institutions. Therefore, S.E.S. Crawford and E. Ostrom (1995, pp. 583-586) developed the grammar of institutions, which is recognized as a general agreement about how to communicate in a consistent language among researchers of institutions.

The studies within the field of institutional character collected for the purpose of this paper focus on diverse features of institutions, which make institutions distinctive when it comes to the character of their change. One of such contentious issues concerns the perception of organization in the context of the institution, whether it is just one type of institution or the agent of change (North, 1990, s. 5). Another special feature of institutions is rooted in the studies of public goods. If it should be provided in an optimal way by the state (Samuelson \& Nordhaus, 1998, p. 509) or the private sector (Holcombe, 1997, pp. 7-8), reducing the free rider problem (Kosfeld et al., 2009, p. 1335), the risk 
of dilemma of endogenous institution formation, and crowding out effect $(\mathrm{Bu}-$ chanan, 1968). Very often the process of change is initiated by a technological factor, trust and social capital or even climate change which have significant impact on the quality of institutions, their structure and process of change (Nooteboom, 2007, pp. 44-45). Researchers explore conditions and processes through which entrepreneurship may influence institutional change. Distinctive character of institutions is investigated in many functional areas of economy, such as education and healthcare system or agriculture etc.

The third set of studies deal with effectiveness of institutions. What are the criteria by which to judge whether an institution is good or bad? Perhaps there is no single answer as an effective institution is a combination of many criteria depending on time and goals. It is recognized that institutions should protect contract or property rights, etc. However, there are multiple ways of achieving these goals and reducing inadequacies or implementing reforms of institutions (Rodrik, 2008, p. 100). Thus reforms in each country should be evaluated relative to its own institutional opportunities, rather than some idealized benchmark (Djankov et al., 2003, pp. 614-615). Hence, D. North (1990, pp. 92-118) recommended 'adaptive efficiency' instead of 'Pareto efficiency' (Caballero \& Soto-Onate, 2015, p. 963).

The next group of studies that have an impact on institutional changes is the institutional actor field, which focuses on the role and context of actors involved in the process of the change of institutions. The analysis of institutional change requires understanding of the micro-level, meso-level and a macro-level in order to examine how actors are involved in four dimensions of politics: the role of political coalitions, the state as an actor, discursive aspects of policy and politics, the transnational aspects of policy and politics (Jackson \& Deeg, 2008, pp. 696-703). In the context of institutional change four types of actor can be posited and each agent type is associated with a particular mode of institutional change: insurrectionaries, symbionts, subversives, opportunists (Mahoney \& Thelen, 2010, pp. 23-27).

The last category of studies belonging to the field of institutional change deals with principles that directly shape the process of institutional change. The socioeconomic environment itself can have an impact on institutional change (Cohen, 2014, p. 230). In the light of that, the interlinking of past, present, and future institutions can be described by three mechanism of change: dynamic institutional complementarities, overlapping social embeddedness, and Schumpeterian bundling innovation (Aoki, 2007, pp. 25-29). Based on the concept of ceremonial encapsulation and its three types the past-binding type, the future-binding type and the Lysenko type can be distinguished (Bush, 1987, pp. 1078-1099). The four main viewpoints on institutional change are institutional design, adaptation, diffusion and collective action (Hargrave \& Van de Ven, 2006, pp. 867-868). Additionally, 'mechanisms for change (...) can be divided into relatively self-conscious and unconscious process of change' (Ostrom \& Basurto, 2011, p. 325). An institutional change takes place at different levels 
of institutions. The first is a change in the social embeddedness, the second is institutional environment, the third relate to government, the latter concern resource allocation (Williamson, 2000, pp. 596-600).

The above-mentioned studies provide common fundamentals for scientists who are able to gain wider and more transparent outlook on empirical and theoretical research, and can choose accurately the object and target, or more precisely identify problems of the research of institutional changes.

\section{Methods}

In order to define the main streams of the institutional change research this study makes use of comprehensive literature research. Economics of institutions is a broad and relatively well investigated discipline but due to lack of thorough research in its many niches and because there is no single coherent theory that allows to explain in-depth evolution of institutions, understanding the process of institutional change seems to be a complicated task. Attention is drawn to a wide overview of studies that are dealing with many aspects, different fields and elements influencing the process of institutional change.

The paper is based on literature research using sources from EBSCO and JSTOR databases and keywords: 'institutional change', 'institutional change theory', 'evolution of institutions'. The first step was to identify sources whose titles corresponded to the topic and goals of the paper. Altogether, 544 papers were selected, out of which 101 (mostly theoretical) were chosen for further study (based on their abstracts). In the second stage, any article in the reference lists with a title indicating the relationship with the topic and goals of the paper was also retrieved and reviewed. In this way, 57 further various critical references to theoretical and some empirical studies were used, predominantly of recent literature, but also certain references to fundamental works were made. In effect, 57 such papers were identified and read. Altogether, 158 papers were analyzed using the inductive approach. The results from different papers, relationships that came to light in the context of multiple studies and aggregated information allowed me to group the studies, moving from specific observations to broader generalizations, into 5 different fields and 14 dimensions. These five fields can be perceived as the main streams of the institutional change research area. The 158 papers were attributed to at least one of the fields and dimensions. On the whole, 231 assignments were made.

\section{Results}

Mainstreams and dimensions within research on institutional change have been arrived at as a result of comprehensive literature analysis. The results of the synthesis are described and summarized in table 1 . The diversity of endogenous and exogenous variables, linkages with specific patterns, and components operating in different fields of the research area of institutional change form a whole 
'machinery of change', that should not be considered separately. Scheme 1 presents a multi-faceted viewpoint of the research area proposed.

Institutional change refers to theories and findings of the studies in the social sciences, sociology and psychology, but especially in economics and its sub-discipline of economics of institutions, which put forward many theories of institutional change. The theories postulated are based on empirical and theoretical studies which can be grouped in one of the five synthesized fields.

The first of them is the elementary institutional field, that can be divided into: definitions, typology and grammar. Definitions include papers about boundaries of institutions and basic terms indispensable for the coherence of the study of institutions. Typology systematizes diversity and multitude of institutions. The grammar of institutions studies essential institutional components and their types, such as norms, rules and strategies and brings mutual understanding among researchers. All these three groups provide elementary knowledge and instruments necessary to investigate evolution of institutions.

The second is the institutional character field which analyzes institutions in specific conditions having impact on the process of institutional change. Special features and effects consider the role of organizations, nature of public goods or common-pool resources as institutions and economic effects that can shape emergence of institutions. The factors group studies of technology, climate change or trust, etc. as forces reconstructing institutions. The functions $\&$ sectors describe peculiarity of institutions in different sectors and functions of the economy. The trends \& social movements explore pressure of the globalization, entrepreneurship or feminism etc. on the process of institutional change.

The next sub-class of the research area is the institutional effectiveness field, consisting of two categories: measures and evaluation \& quality. The former focuses on creating KPIs, instruments and methodologies for assessing institutions. The latter deals with the problem of defining effectiveness and what does being a good or bad institution mean, whether adaptive or Pareto's approach to effectiveness is better, searching for best-practice, good economic and social relations and preferable patters, defining proper goals, structures and functions of institutions.

The fourth set of papers is the institutional actor field that incorporates the role of the actor in the study of institutional change. The roles collection of studies explains types, roles of agents in different situations, levels or phases of change and what is the scope of positions they can take etc. The strategies \& behaviors exemplify how actors react in order to preserve or change institutions, what is the scope of actions they can take, etc.

The most important category of studies is the institutional change field which analyzes directly environments, mechanism and levels \& phases of institutional change. The external aspects, such as the types of the capitalistic or socioeconomic systems, create environment which influences institutions and, simultaneously, can itself be affected by institutions. The mechanism aggregation studies search for patters and ways of explaining how institutions can change. 
The levels \& phases articles investigate how the process of change differs at particular levels of institutions or phases of the evolutionary transition.

The findings from all fields mentioned above and dimensions of the research area influence each other enriching the knowledge we pose about institutional change. The scheme of the multi-faceted viewpoint facilitates in-depth understanding of the landscape of institutional changes, which is the main value of this study.

\section{Conclusion}

Most aspects of institutional change studies can be assigned to one of the five distinguished main streams of the research area. However, it is difficult to identify all of them because of the limitation of scope of literature analysis conducted for the purpose of this paper, which should be seen as a first step towards a wider future considerations about multi-faceted viewpoint of the institutional change research. The attempt to isolate the mainstreams of the research allows to outline recent outcomes and evaluate the directions of further research. More attention should be paid to the 'machine approach' to investigate relations between fields, various elements, and components involved in the process of change and how different combination of them impact on the evolution of institutions. New aspects should still be found and explored in order to gain deeper insights into the dynamics of institutional change.

\section{References}

Aoki, M. (2007). Endogenizing institutions and institutional changes. Journal of Institutional Economics, 3(1). doi:10.1017/S1744137406000531.

Buchanan, J.M. (1968). The demand and supply of public goods. Retrieved 25.03.2018 from http://www.econlib.org.

Bush, P.D. (1987). The theory of institutional change. Journal of Economic Issues, 21(3). doi:10.1080/00213624.1987.11504697.

Caballero, G., \& Soto-Onate, D. (2015). The diversity and rapprochement of theories of institutional change: original institutionalism and new institutional economics. Journal of Economic Issues, 49(4). doi:10.1080/0021362 4.2015.1105021.

Cohen, S.I. (2014). Different institutional behavior in different economic systems: theory and evidence on diverging systems worldwide. Economic Systems, 38(2). doi:10.1016/j.ecosys.2013.08.003.

Crawford, S.E.S., \& Ostrom, E. (1995). A grammar of institutions. American Political Science Review, 89(3). doi:10.2307/2082975.

Davis, L., \& North, D. (1970). Institutional change and American economic growth: a first step towards a theory of institutional innovation. The Journal of Economic History, 30(1). doi:10.1017/s0022050700078633. 
Djankov, S., Glaeser, E., La Porta, R., Lopez-de-Silanes, F., \& Shleifer, A. (2003). The new comparative economics. Journal of Comparative Economics, 31(4). doi:10.1016/j.jce.2003.08.005.

Hargrave, T.J., \& Van de Ven, A.H. (2006). A collective action model of institutional innovation. Academy of Management Review, 31(4). doi:10.5465/ amr.2006.22527458.

Holcombe, R.G. (1997). A theory of the theory of public goods. The Review of Austrian Economics, 10(1). doi:10.1007/BF02538141.

Jackson, G., \& Deeg, R. (2008). From comparing capitalisms to the politics of institutional change. Review of International Political Economy, 15(4). doi:10.1080/09692290802260704.

Kosfeld, M., Okada, A., \& Riedl, A. (2009). Institution formation in public goods games formation in public goods games. American Economic Review, 99(4). doi:10.1257/aer.99.4.1335.

Mahoney, J., \& Thelen, K. (2010). A theory of gradual institutional change. In J. Mahoney, \& K. Thelen (Eds.), Explaining institutional change. Ambiguity, agency, and power. New York: Cambridge University Press.

Nooteboom, B. (2007). Social capital, institutions and trust. Review of Social Economy, 65(1). doi:10.1080/00346760601132154.

North, D. (1990). Institutions, institutional change and economic performance. Cambridge: Cambridge University Press. doi:10.1017/CBO9780511808678.

Ostrom, E., \& Basurto, X. (2011). Crafting analytical tools to study institutional change. Journal of Institutional Economics, 7(3). doi:10.1017/ S1744137410000305.

Rodrik, D. (2008). Second-best institutions. American Economic Review, 98(2). doi:10.1257/aer.98.2.100.

Roland, G. (2004). Understanding institutional change: fast-moving and slow-moving institutions. Studies in Comparative International Development, 38(40. doi:10.1007/BF02686330.

Samuelson, P.A., \& Nordhaus, W. (1998). Ekonomia 2. Warszawa: PWN.

Williamson, O.E. (2000). The new taking institutional economics: taking stock, looking ahead. Journal of Economic Literature, 38(3). doi:10.1257/jel.38.3.595.

\section{Acknowledgements}

Author contributions: author has given an approval to the final version of the article.

Funding: this research was undertaken as part of the doctoral research project and was fully funded by the author.

Supplementary information: author acknowledge following people and institution for help with the preparation of the article: Milena Ratajczak-Mrozek, Jan Polowczyk, Tadeusz Kowalski.

Note: the results of this study were presented at 9th International Conference on Applied Economics Contemporary Issues in Economy (June 22-23, Torun, Poland). 


\section{Appendix}

\section{Table 1.}

\section{Mainstreams and dimensions of institutional change's research}

\begin{tabular}{llc}
\hline Fields of the research area (mainstreams) & Dimensions of the research area & No. of papers (aspects) \\
\hline \multirow{2}{*}{ the elementary institutional field } & definition & 24 \\
& grammar & 10 \\
& typology & 13 \\
the institutional character field & special features \& economic effects & 25 \\
& factors of change & 22 \\
\hline \multirow{2}{*}{ the institutional effectiveness field } & sectoral \& functional specificity & 13 \\
\hline \multirow{2}{*}{ the institutional actor field } & trends \& social movements & 13 \\
& evaluation \& quality & 10 \\
\hline & measurements & 11 \\
the institutional change field & roles & 11 \\
\hline
\end{tabular}

Source: Own preparation. 
Scheme 1 .

The multi-faceted viewpoint of the mainstreams of the institutional change

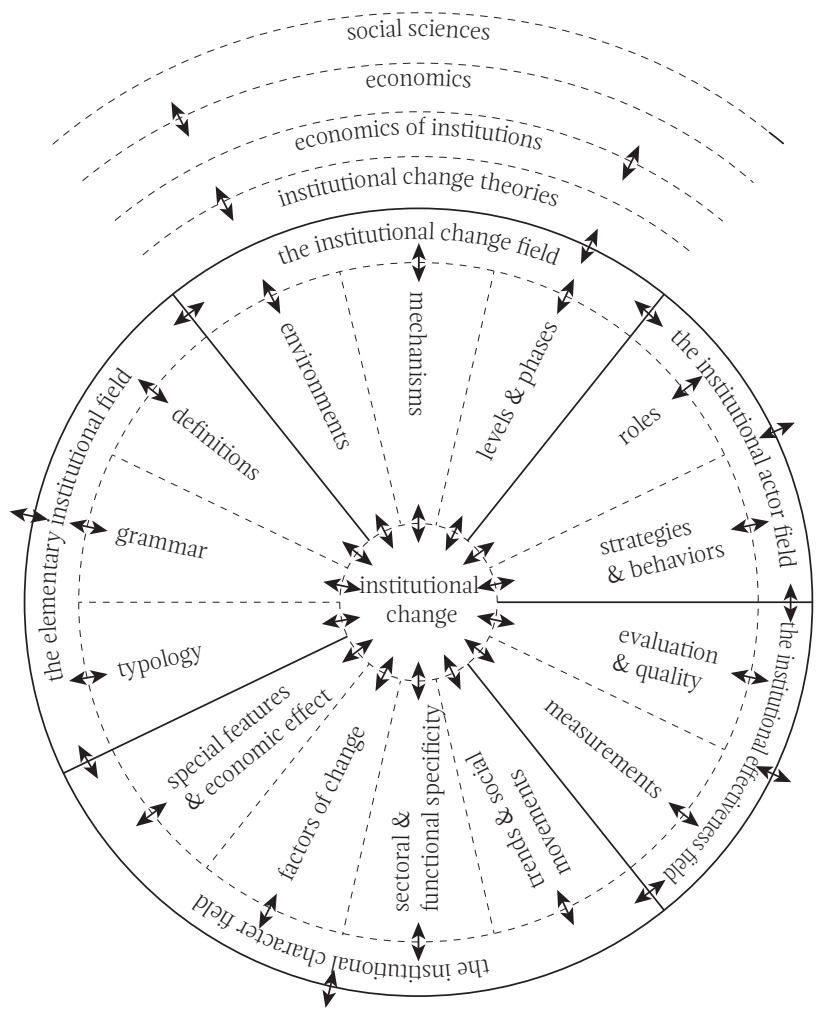

Source: Own preparation. 
